\title{
Pollution effects on fisheries - potential management activities
}

\author{
C. J. Sindermann
}

\author{
U. S. Department of Commerce, National Oceanic and Atmospheric Administration, \\ National Marine Fisheries Service, Northeast Fisheries Center, Sandy Hook Laboratory; \\ Highlands, New Jersey 07732, USA
}

\begin{abstract}
Management of ocean pollution must be based on the best available scientific information, with adequate consideration of economic, social, and political realities. Unfortunately, the best available scientific information about pollution effects on fisheries is often fragmentary, and often conjectural; therefore a primary concern of management should be a critical review and assessment of available factual information about effects of pollutants on fish and shellfish stocks. A major problem in any such review and assessment is the separation of pollutant effects from the effects of all the other environmental factors that influence survival and well-being of marine animals. Data from long-term monitoring of resource abundance, and from monitoring of all determinant environmental variables, will be required for analyses that lead to resolution of the problem. Information must also be acquired about fluxes of contaminants through resource-related ecosystems, and about contaminant effects on resource species as demonstrated in field and laboratory experiments. Other possible management activities include: (1) encouragement of continued efforts to document clearly the localized and general effects of pollution on living resources; (2) continued pressure to identify and use reliable biological indicators of environmental degradation (indicators of choice at present are: unusually high levels of genetic and other anomalies in the earliest life history stages; presence of pollution-associated disease signs, particularly fin erosion and ulcers, in fish; and biochemical/physiological changes); and (3) major efforts to reduce inputs of pollutants clearly demonstrated to be harmful to living resources, from point sources as well as ocean dumping. Such pollution management activities, based on continuous efforts in stock assessment, environmental assessment, and experimental studies, can help to insure that rational decisions will be made about uses and abuses of coastal/estuarine waters.
\end{abstract}

\section{INTRODUCTION}

Pollution effects on fisheries, and the possible management activities that should be undertaken to reduce any demonstrated effects, have occupied the attention of environmental scientists in the Middle Atlantic Bight of the North American east coast for more than a decade, principally because of the extent of estuarine-coastal pollution resulting from the great concentrations of humans on adjacent shores (Gross, 1976). In that area, if anywhere in the world, it should be possible to confront the persistent questions of pollution impacts on resource species, and to find generic answers, which may have application in other less degraded waters of the planet. In that area, too, scientists are on notice by environmental and resource managers to give them definitive information, or to withdraw to the laboratory and be very quiet.

It seems that there are two rather clear-cut responsibilities when considering 
pollution effects on fisheries: one is to demonstrate that estuarine/coastal pollution is really affecting fish and shellfish stocks, and the second is to propose management measures to mitigate damage if it exists.

These responsibilities can be satisfied in five stages, which are easy to state but difficult to accomplish: (1) isolate and quantify pollution effects on resource species - as distinct from effects of natural environmental variations; (2) conduct critical examinations of pollution effects at levels of the individual, the local population, and the species; (3) encourage the identification and quantification of sensitive early-warning indicators of environmental degradation; (4) attempt to reduce pollutant inputs, where damage to living resources has been or can be demonstrated; and (5) carry out pragmatic regulatory activities to protect public health.

Each of these activities will be considered briefly in the following sections. Because of the limitations of space in this report much substantive material must be ignored or treated inadequately, but the other papers in this symposium on "Protection of Life in the Sea" should serve to correct at least some deficiencies.

\section{ISOLATION AND QUANTIFICATION OF POLLUTION EFFECTS ON RESOURCE SPECIES AS DISTINCT FROM EFFECTS OF NATURAL ENVIRONMENTAL VARIA- TIONS}

Looking at the history of fished populations and their changes in abundance, it is disconcerting that after many decades of scientific research, we are still unable to assign specific responsibilities for observed fluctuations in abundance. A simplistic view of cause and effect is not realistic, since very complex ecosystem interrelations are involved. Many factors undoubtedly account for the great variation in fish abundance, and the complexity of the problem is further increased by variability in sampling techniques designed to determine abundance. Just as an example, we might consider the Atlantic herring, Clupea harengus, a species that has been studied for over half a century in North America and almost a century in Europe. A pervasive question, even today, is that of causes of fluctuations in year class strength. We have learned much about herring biology, and about some effects of temperature, food availability, storms, competition, and predation on survival of early life history stages, but full understanding of why year classes are strong or weak in any given year is still elusive, as it is for many other commercial fishes.

To sort out pollution effects on species such as herring (or any other commercial species) from effects of many other environmental variables is an overwhelming assignment - almost at times like an exercise in futility - and yet it must be done if biologists expect to make any impact on the legal and political processes that govern decisions about ocean dumping, effluent controls, and stock management in response to pollution problems. To hope to make even a slight impression on the sorting-out process, we need to: (1) understand the relative importance of all environmental factors in modifying mortality rates of fish and shell-fish at all stages in their life histories; (2) define the role of pollutants in affecting abundance; (an approach might be quantitative studies of pollution effects on key indicator species in clean, lightly impacted, moderately impacted, and heavily impacted habitats); and (3) examine chronic effects as well as acute mortality effects of pollutants. 
To be able to recommend management strategies, effects of all environmental variables, including specific contaminants, must be examined for all life history stages (Fig. 1). A few case history studies of species from the western North Atlantic might be instructive.

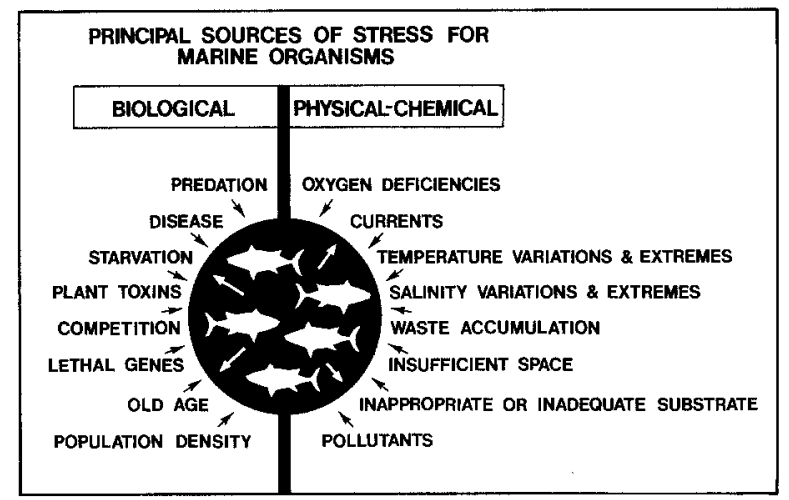

Fig. 1. Principal sources of environmental stress for marine animals

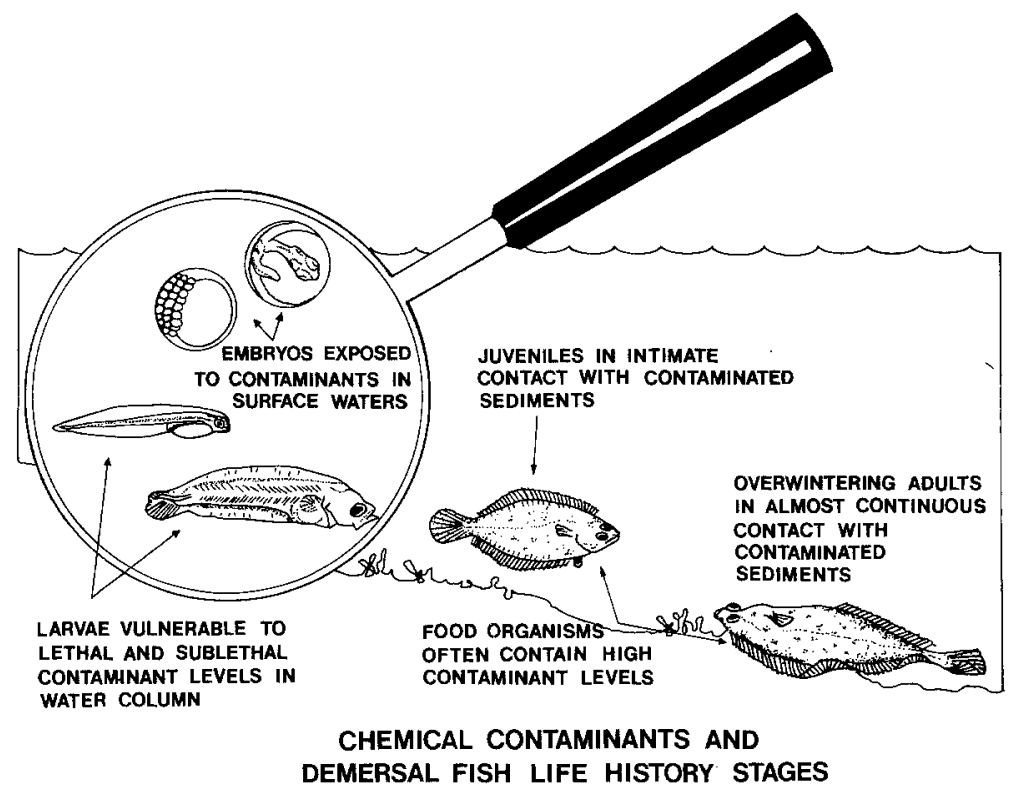

Fig. 2. Life cycle of the winter flounder Pseudopleuronectes americanus with potential pollutant impact points 


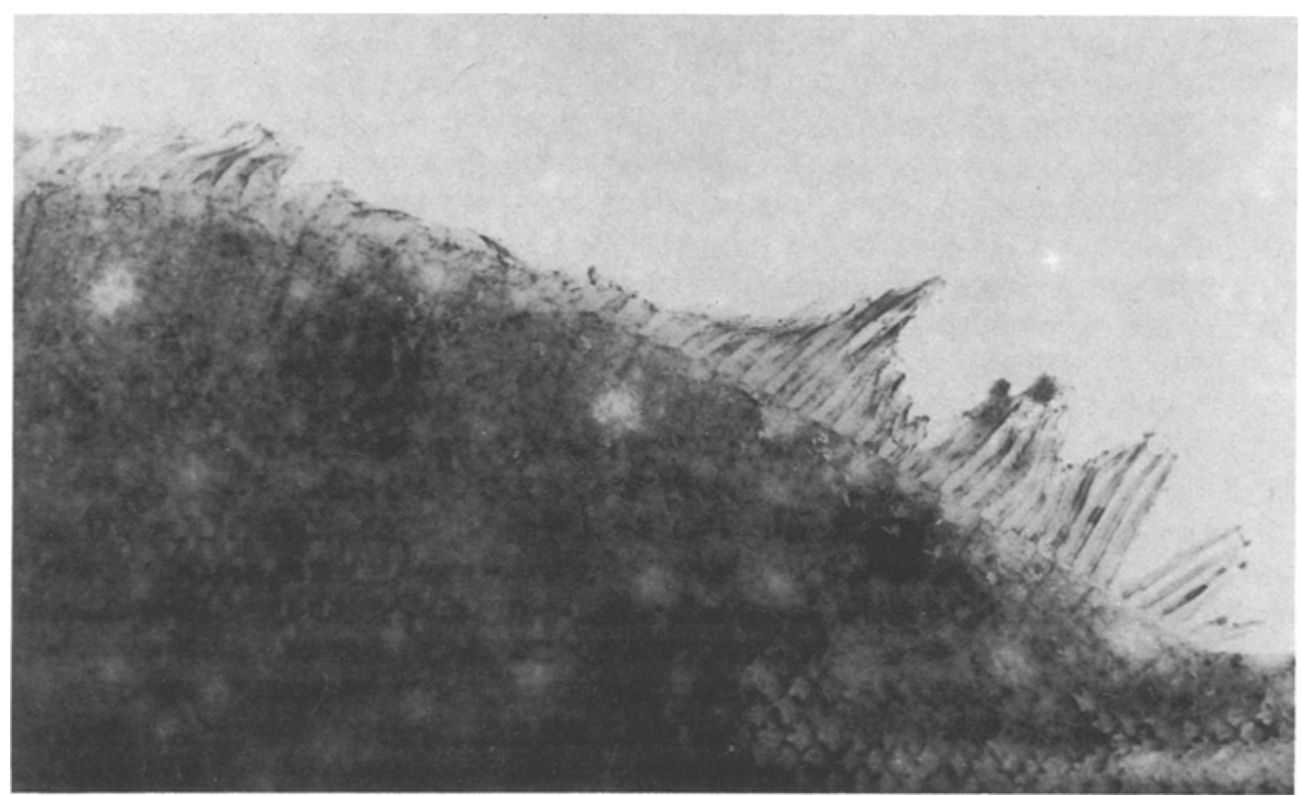

Fig. 3. Fin erosion in summer flounder Paralichthys dentatus from the New York Bight

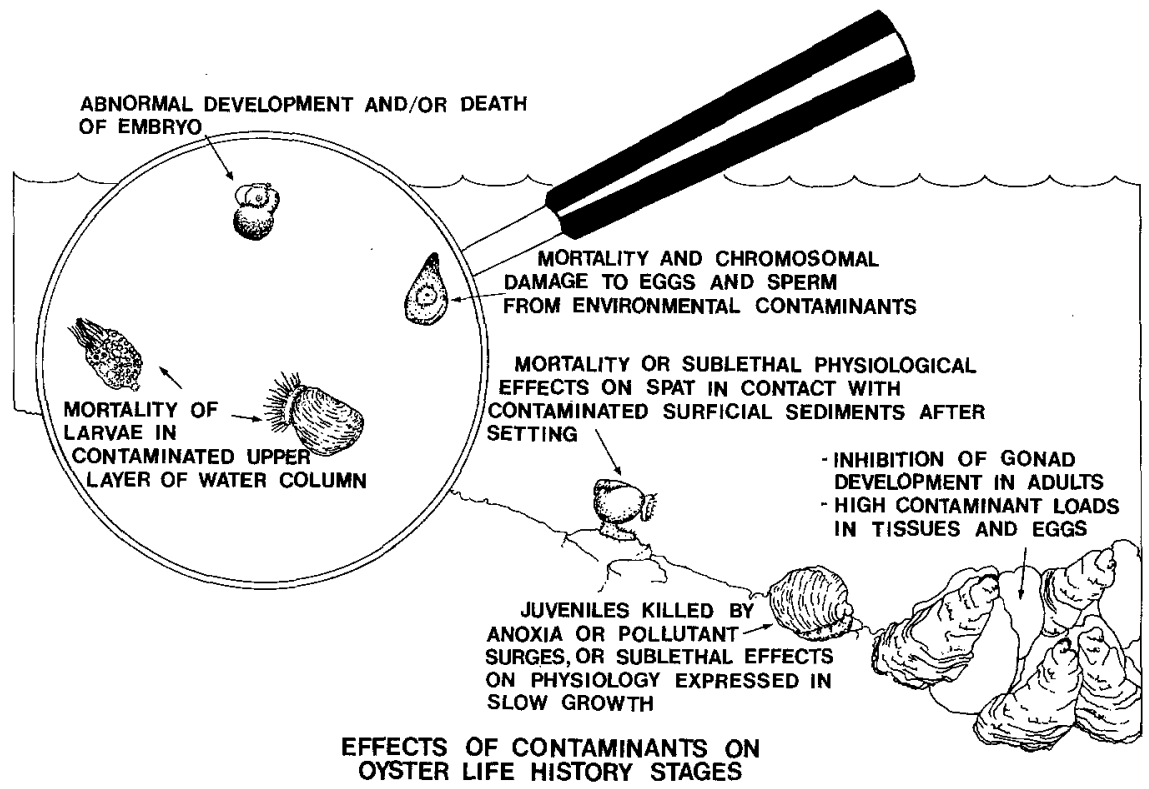

Fig. 4. Life cycle of the American oyster Crassostrea virginica with potential pollutant impact points 
The first example is the winter flounder Pseudopleuronectes americanus (Fig. 2). The female produces an average 600,000 eggs, of which an estimated 10-16 percent hatch. Only an estimated 18 individuals per 100,000 hatched larvae survive to age one (Saila, 1962). The species is estuarine dependent, both for nursery areas and for overwintering sites for adults. Many estuaries are polluted, and adults are in intimate contact with polluted sediments. Fin erosion is a common disease in such fish; Figure 3 shows such fin damage in summer flounder. Catches over the past 25 years in the Middle Atlantic Bight have been constant, without any major trend.

Another example is the American oyster Crassostrea virginica (Fig. 4). Spawned eggs of this species may number more than 100 million; larval planktonic life is 2-3 weeks; and newly set spat are subject to intense predation, and must compete with many fouling organisms. Oyster populations on the United States east coast have declined because of poor management and disease-caused mass mortalities (Fig. 5). There have been localized disappearances of oyster populations that are unrelated to pollution, but

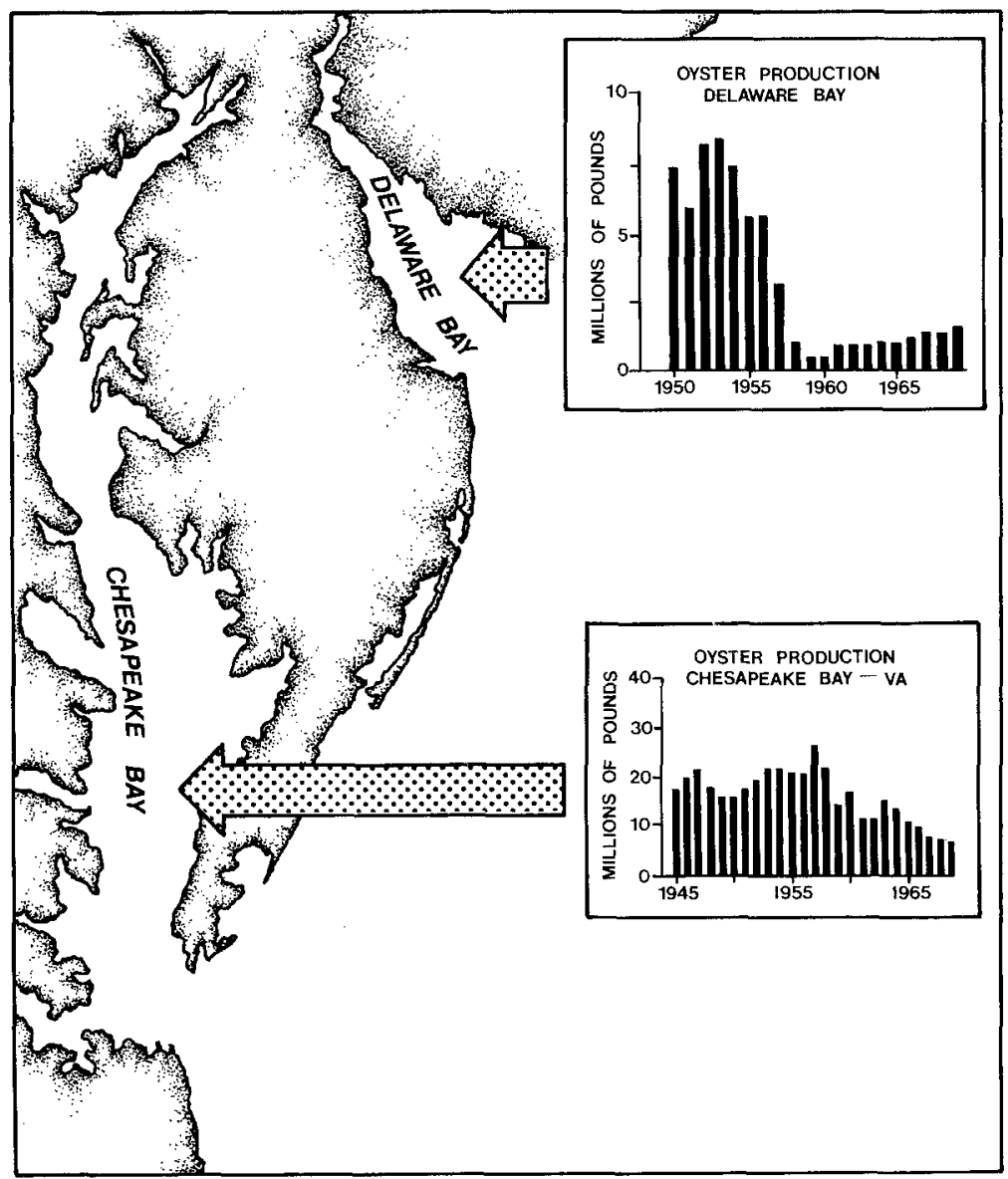

Fig. 5. Decline in oyster production in Delaware and Chesapeake Bays (USA) following a disease outbreak which began in the late 1950's 
some disappearances in heavily contaminated bays may be related to pollution (Nelson, 1916).

A final example is the striped bass Morone saxatilis (Fig. 6). This species has had a history of violent fluctuations in catch (and presumably abundance); its center of abundance is Chesapeake Bay, with lesser centers in the Hudson and Delaware estuaries; and turbidity may favor egg and larval survival (Mansueti, 1962). The trend in the last two decades has been irregularly upward.

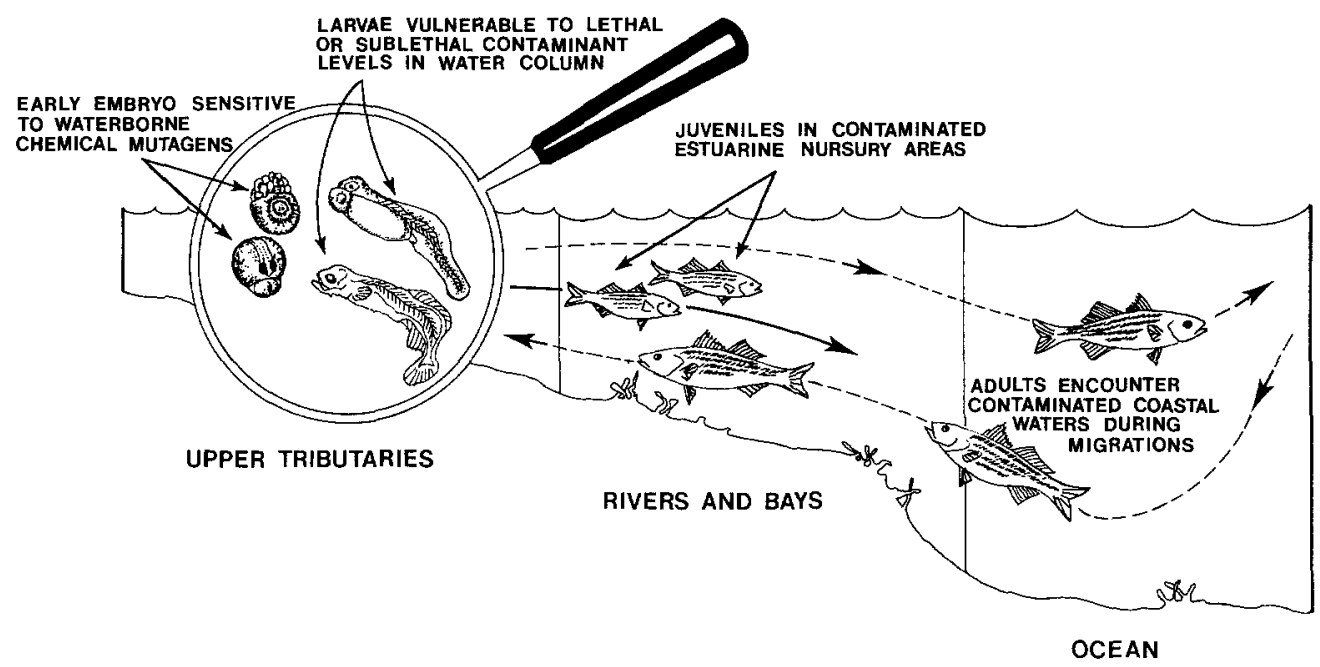

Fig. 6. Life cycle of the striped bass Morone saxatilis with potential pollutant impact points

The dimensions of the problem of isolating natural from man-made environmental forces should be apparent from these few examples of species which might be expected to show affects of pollution. The task is difficult but not impossible for quantitative biologists, if adequate environmental and fisheries data are available (a very important qualification).

\section{CRITICAL EXAMINATION OF POLLUTION EFFECTS AT LEVELS OF THE INDI- VIDUAL, THE LOCAL POPULATION, AND THE SPECIES}

Human activity has increased environmental stresses on fish in estuarine and coastal waters. We have, for instance, added pesticides and other synthetic chemicals which can, even in low concentrations, drastically affect the physiology of fish and shellfish and with which the species may have had no previous evolutionary experience. We have added heavy organic loads, in the form of sewage sludge and effluents, which can produce anaerobic or low-oxygen environments, and which are often accompanied by other contaminants such as heavy metals, that can interfere with enzymes of the fish and the food organisms they consume.

In recent decades there has been a gradual increase in the extent of polluted coastal/ estuarine areas - an increase that is generally proportional to the density of the adjacent human population and its level of industrialization. Excellent documented examples of 
this phenomenon exist in North America, with counterparts in Europe and elsewhere in the world.

That chemical pollutants cause stress and death in individual marine animals can be easily demonstrated, and has been repeatedly. Descriptions of lethal and sublethal effects of heavy metals, petroleum compounds and halogenated hydrocarbons abound in the experimental literature.

That stress from chemical pollutants can have significant quantifiable effects on resource species abundance (apart from localized effects in severely contaminated coastal and estuarine zones) is much more difficult to demonstrate, and has not been documented satisfactorily.

The previous section of this paper included an examination of some case histories of points in the life cycles of fish and shellfish where pollutant stressors can exert lethal and sublethal influences. From experimental studies it seems obvious that with all these potential impact points throughout life cycles, populations in contaminated waters should dwindle and disappear, yet from experience on the North American east coast this has not happened. Only in severely degraded local waters, which are a tiny part of the total range of most fish and shellfish, have there been localized disappearances of some species; even in those areas, other species which might be expected to be affected, are still present and are in some instances abundant. This is true particularly of a number of coastal estuarine-dependent fish species, many of whom spend much of their life cycles in waters that are to some extent contaminated.

A recent review of the fishery resources of the United States (Wise, 1974) discussed catches of all important marine fish and shellfish, on a species by species basis, for the past 20 years. Included were the major Atlantic species usually considered estuarine dependent or estuarine and nearshore inhabitants, species which might be expected to demonstrate some effects of estuarine and coastal pollution. With few exceptions, according to that publication, catches of those species have been relatively steady or have shown some increases in the past 20 years. One of the summarizing statements in the report is of particular note: "In general there are no good fishing effort data available for those estuarine species whose catches have remained constant, so it is possible that maintenance of catch levels is due to constantly increasing fishing effort. Nonetheless, the evidence from catch records of a substantial number of exploited estuarine species in United States waters indicates that pollution and damage to estuaries have not yet shown any measurable overall effect on the part of the marine resource which might be expected to show the first effects."

This, of course, discounts the possibility that anadromous or estuarine species may be resistant to at least some man-made environmental changes, and that species such as striped bass may actually benefit from certain environmental alterations (increased turbidity, for example). Intensive foreign fishing, in some instances probably beyond the maximum sustainable yield of certain species, has probably exerted a much more severe impact on a number of major fish stocks in U. S. continental shelf waters than has pollution, insofar as such effects can be determined. However, most of the stocks affected by foreign fishing are not the ones which would be most directly affected by estuarinecoastal pollution:

It seems relevant to this discussion that a recent attempt by Cole (1975) to assess pollution effects on North Sea fish and shellfish stocks also disclosed no identifiable 
widespread damage that could be directly attributable to pollutants. Only shrimp populations seemed to be affected negatively, while principal demersal fish species such as cod, haddock and plaice have increased in abundance in recent years.

But there is a basic and ultimate fallacy to this entire line of reasoning. To insist on demonstration of easily discernible effects on overall species abundance is to establish too harsh a criterion of pollution damage. A much more acceptable concept is that effects of pollution, clearly demonstrated on even a single individual or a local population, must be considered a cause for management action to protect the total population - just as is the case with humans. All the mechanisms of public health protection come into force when even mediocre statistical correlations of pollution and human disease are made; and the same kinds of responses should be made by resource and environmental managers when correlations of pollution and fish abnormalities are found. At present such responses are not made; the evidence is considered as mildly interesting, but not as a cause for panic, or even for moderate action.

A number of early warning signs of environmental degradation and potential impacts on living resources are becoming apparent and available to managers, and this is the subject of the next section of this paper.

\section{IDENTIFICATION OF SENSITIVE EARLY WARNING INDICATORS OF ENVIRON- MENTAI DEGRADATION}

It would seem almost axiomatic that death and disappearance are too extreme as criteria for determining whether pollutants are harmful to marine biota or not. The more subtle sublethal effects of pollutant stress should be examined as indicators of possible longer-term impacts on populations that as yet are difficult to quantify. These sublethal effects can take many forms of course - physiological and biochemical alterations, behavioral changes, ecological changes, and pathological changes.

A recent and excellent workshop on biological effects monitoring (McIntyre, 1978) described a number of sensitive biological indicators of pollution stress - but found few that were ready for present quantitative application without further research and development.

The best candidates, which are "on line" and beginning to be applied quantitatively in the northeastern United States and a few other places, consist of several pollutionassociated pathologies (Sindermann, 1979). Diseases and abnormalities in several categories can provide excellent clues about the extent of degradation and the degree of risk for marine populations in any specified polluted habitat. Pathology must be taken in its broadest sense, to include everything from chromosomal damage in the developing egg, to ultrastructural changes in gill epithelium, and to tumors, infectious diseases, and skeletal anomalies.

Of the pathologies that seem reasonably related to pollution, there are three categories that can be taken "off the shelf" immediately and applied to a biological monitoring program:

(a) Cytologic and cytogenetic damage to eggs, embryos, and larvae resulting from exposure to contaminants. This relatively new research area can be called "chromosome pathology" - the effects of contaminants on the genetic material of early life history stages, and the effects of such damage on survival of offspring and on population 
abundance. Chromosomal and cytological anomalies have been found with high prevalence in polluted coastal waters (Longwell, 1976).

(b) Fin erosion and ulcerations of the body associated with exposure to degraded environments. These conditions have been reported from polluted waters in many parts of the world, and in some instances have been shown to have statistical correlation with degree of degradation in water quality (Murchelano \& Ziskowski, 1976).

(c) Latent infections, particularly those of viral etiology, which may be provoked into active disease by pollution stress. There has been an explosion of information about viruses in marine animals in the past few years, and pollutant stress may be one way of elucidating their effects on marine animals. Several viral diseases of fish and invertebrates have been recognized after exposure to pollutant stress (Farley et al., 1972; Couch, 1974; Buchanan et al., 1978).

The concept to be advanced here is that "epizootic" levels of these abnormalities can be powerful diagnostic tools in recognizing areas of pollution stress - areas where effects on fishery resources might be expected.

The level of sensitivity of the approaches outlined above is good, but still crude when compared with techniques which are in the research phase but not yet operational. Very subtle changes, such as pre-neoplastic tissue changes, ultrastructural alterations in epithelium, and reduced immunocompetence, can augment the " on line" approaches soon, as early warning signs of increasing environmental stress. Resource managers should make full use of the most sensitive indicators of habitat degradation that are available.

While certain pathological indicators seem to be of greatest potential utility in effects-monitoring programs at present, there are also physiological, biochemical, behavioral and ecological indicators that may be useful. A single universal indicator is unlikely; a multidisciplinary approach to biological effects monitoring should be used.

\section{REDUCTION OF POLLUTANT INPUTS, WHERE DAMAGE TO LIVING RESOURCES HAS BEEN OR CAN BE DEMONSTRATED}

Once the steps outlined so far have been taken - (1) pollution effects have been separated from those due to natural factors; (2) pollution effects on individuals, populations, and species have been examined; and (3) sensitive indicators of environmental degradation have been identified and tested - then it should be possible to confront the real management function: to attempt to reduce pollutant inputs, where damage to living resources has been demonstrated.

To be able to have an effective case against increasing coastal/estuarine pollution, and to begin to reverse the trend, we must be able to demonstrate effects, and not merely to hypothesize them. There are only a few places in the world where effects have been demonstrated adequately; the New York Bight is one such place. In this, one of the most severely degraded coastal water areas in the entire world, a number of environmental changes have been seen: (a) reduced species diversity; (b) reduced biomass in heavily impacted zones; (c) abnormal fish and shellfish; and (d) high sediment and tissue levels of contaminants.

An intense struggle for control of coastal waters in the New York Bight is taking place right now. The United States Environmental Protection Agency has announced 
that ocean dumping in this area (and elsewhere) will cease by the end of 1981 . Arguments for continued dumping being raised by those doing the dumping include the following:

"Alternatives to ocean dumping are too expensive, and the technology is not available;" "Scientists have not proved adequately that there is more than very localized damage to coastal ecosystems;" and "Ocean dumping may represent the best use of certain ocean areas adjacent to large human populations."

The expectation of environmental managers is, of course, that once pollutant inputs to this or any other affected area have been reduced or eliminated, then positive changes may occur. Several studies elsewhere have provided evidence that this hope can be realized, however slowly. Examples include the reduced levels of DDT in sediments on the California coast following elimination of contaminated effluent (MacGregor, 1971, 1976), and reduced PCB contamination in Escambia Bay, Florida, as a result of expressed public concern about chemical plant effluents containing the pollutant (Duke et al., 1970). Numerous other localized positive responses to pollution abatement needs could be cited, but most of them are in fresh waters, and many of the steps taken result in decreases in river pollution but increases in estuarine/coastal pollution.

One concept which encompasses a large amount of fallacy, but which has been applied often, is that of "acceptable levels" or "maximum permissible levels" of potentially toxic contaminants in the oceans. A logical question is "Acceptable to whom?" - Certainly not to the marine organisms whose environment is being modified, and certainly not to the resource manager, who must be concerned about long-term sublethal effects and bioaccumulation of certain toxic chemical pollutants in commercial fish and shellfish. There is and will be intense competition for primary uses of estuarine/ coastal waters. It is repugnant to many fisheries biologists to even consider that the primary use of these waters can be as a dump for toxic wastes of human society. Living resources, now and for the future, require better representation from scientists than that which would allow continued habitat degradation - even under the guise of "multiple uses" of estuarine/coastal waters.

\section{PRAGMATIC REGULATORY ACTIVITIES TO PROTECT PUBLIC HEALTH}

Reduction of pollutant inputs to estuarine/coastal waters is a necessary and worthwhile objective, but one which requires time and great effort by environmental protection agencies - local, national and international. In the interim there are other more pragmatic management activities that can and must be carried out, as a means of protecting public health, but not necessarily the health of living marine resources. These measures include enforcement of regulations concerning closure of shellfish areas subject to excessive inputs of contaminants; and bans on sale of fishery products found to contain excessive levels of contaminants.

To counterbalance these necessary but negative regulatory functions, there are a number of mitigating actions that are sometimes and should always be a part of management programs: (a) depuration of shellfish - possibly as a universal requirement, as it is in some European countries at present; (b) relaying of shellfish from contaminated areas, with government support if necessary; and (c) continuous surveys of chemical 
contaminant levels in fish and shellfish, to determine geographic variations and trends with time.

Protection of public health always seems to receive a warmer reception from those responsible for enactment and enforcement of laws and regulations than does protection of living resources. Both have a common objective in reducing contaminant levels in fisheries products and hence in the habitats of fish and shellfish, but resource managers probably must accept, however reluctantly, the reality that resource problems will continue to lag behind public health problems in terms of public concern and action. Emphasis on the intimate relationships of the two - public health and resource health can be a fruitful approach to pollution abatement.

\section{CONCLUSIONS}

Pollution effects on fisheries have received some scrutiny in recent decades, and information is accumulating, but is still insufficient to be very useful in resource management decisions - except as they involve local areas. Evidence exists for localized effects of pollutant stress on fisheries, but as yet there is little specific evidence for widespread damage to major fisheries resource populations resulting from coastal pollution. This may well be because we are unable to separate clearly the effects of pollutant stress from effects of the many other forms of environmental stresses to which marine populations are subject. Other factors, such as shifts in geographic distribution of fish populations, changes in productive ecosystems, or overfishing, may cause pronounced changes in fisheries - changes which could obscure any effects of localized habitat degradation. It seems, with the evidence presently available, that factors other than pollution seem to be overriding in determining fish abundance, but we lack

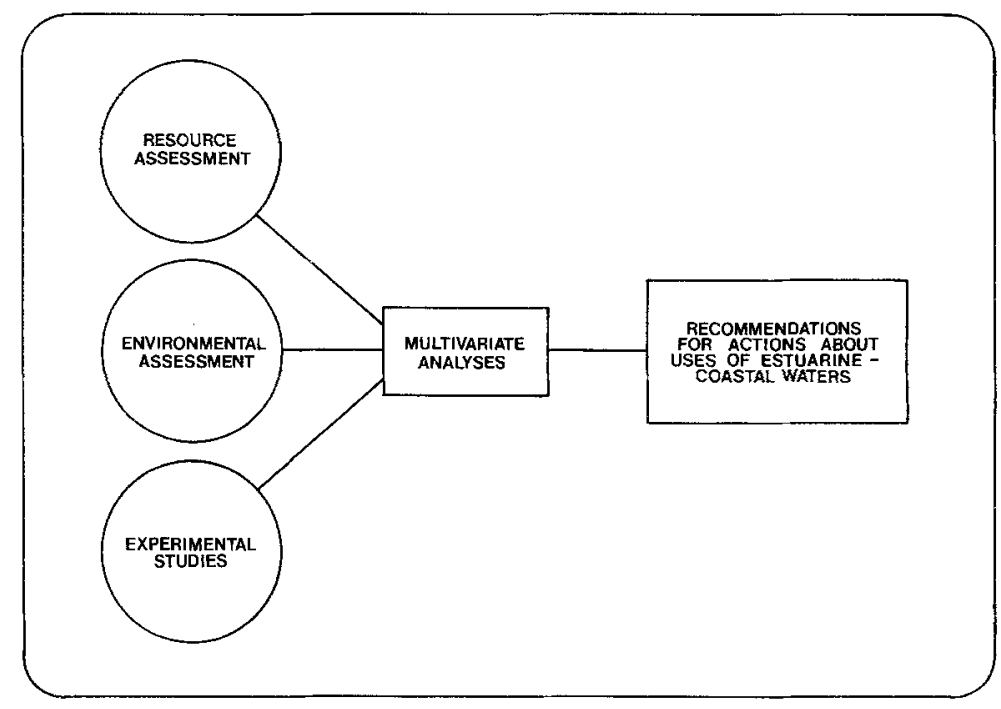

Fig. 7. The research base required to understand pollution effects 
quantitative data to make positive statements about cause and effect relationships of abundance and pollution.

It may be, of course, that estuarine/coastal pollution is exerting some overall influence on certain resource species, but that this influence may be masked by increased fishing effort, or by favorable changes in other environmental factors which create a positive effect on abundance, outweighing any negative effects of pollutants. Many experimental studies, particularly more recent ones concerned with long-term exposure of fish and shellfish to low levels of contaminants, suggest that some long-term effects on abundance should be felt, but our statistics, our monitoring, and our population assessments are not yet adequate to detect them.

Effective long-term monitoring of stocks and environment must be the basis of any attempt to isolate and identify pollution effects. A continuous integrated effort in stock assessment, environmental assessment, and experimental studies (Fig. 7) will be required to understand the role of all environmental stresses - natural and man-induced - in determining abundance of resource populations.

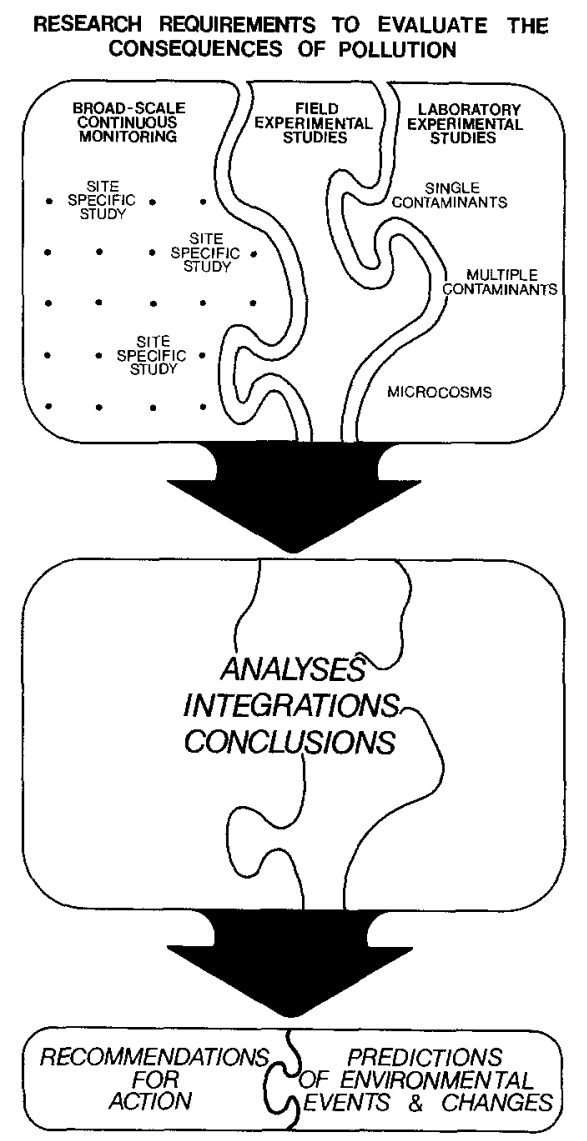

Fig. 8. The sequence of events leading to predictions and management actions 
However, we do not yet have the principal pieces of the puzzle in place (Fig. 8), so in the absence of full understanding of the phenomena involved, management decisions affecting estuarine/coastal pollution must be made on the basis of "best available scientific information," just as decisions about allowable resource exploitation are made. In both types of decision processes, a conservative action provides a lower risk of damage and loss than does a more extreme action. Conservatism can be especially significant when decisions are made that might permit pollution to continue or increase, since long-term effects of existing levels on abundance of resource populations are largely undetermined. In addition to advocating conservatism, we must persist in attempts to quantify the effects of pollution, and to determine the precise pathways through which fishery resources are affected.

\section{LITERATURE CITED}

Buchanan, J. S., Richards, R. H., Sommerville, C. \& Madeley, C. R., 1978. A herpes-like virus from turbot (Scophthalamus maximus L.). - Vet. Rec. 1978, 527-528.

Cole, H. A., 1975. Marine pollution and the United Kingdom fisheries. In: Sea fisheries research. Ed. by F. R. Harden-Jones. Wiley, London, 277-303.

Couch, J. A., 1974. An enzootic nuclear polyhedrosis virus of pink shrimp: Ultrastructure, prevalence, and enhancement. - J. Invertebr. Pathol. 24, 311-331.

Duke, T. W., Lowe, J. I. \& Wilson, A. J. Jr., 1970. A polychlorinated biphenyl (Aroclor 1254) in the water, sediment, and biota of Escambia Bay, Florida. - Bull. environ. Contam. Toxicol. 5, 171-180.

Farley, C. A.; Banfield, W. G., Kasnic, G. Jr. \& Foster, W. S., 1972. Oyster herpes-type virus. Science, N. Y. $178,759-760$.

Gross, M. G. (Ed.), 1976. Middle Atlantic continental shelf and the New York Bight. - Spec. Symp. Am. Soc. Limnol. Oceanogr. 2, 1-441.

Longwell, A. C., 1976. Chromosome mutagenesis in developing mackerel eggs sampled from the New York Bight. NOAA tech. Mem. U.S. Dep. Comm. ERL-MESA-7, 1-61.

MacGregor, J. S., 1971. Changes in the amount and proportions of DDT and its metabolites, DDE and DDP, in the marine environment off southern California, 1949-72. - Fish. Bull., U.S. 72, 275-293.

MacGregor, J. S., 1976. DDT and its metabolites in the sediments off southern California. - Fish. Bull., U.S. 74, 27-35.

McIntyre, A. D., 1978. On the feasibility of effects monitoring. - Coop. Res. Rep., I.C.E.S. 75, 1-42.

Mansueti, R. J., 1962. Effects of civilization on striped bass and other estuarine biota in Chesapeake Bay and tributaries. - Proc. Gulf Caribb. Fish. Inst. 1961, 110-136.

Murchelano, R. A. \& Ziskowski, J., 1976. Fin rot disease studies in the New York Bight. - Spec. Symp. Am. Soc. Limnol. Oceanogr. 2, 329-336.

Nelson, J., 1916. Annual report of the Department of Biology, Rutgers University. New Brunswick, N.J.

Saila, S. B, 1962. The contribution of estuaries to the offshore winter flounder fishery in Rhode Island. - Proc. Gulf Caribb. Fish. Inst. 1961, 95-105.

Sindermann, C. J., 1979. Pollution-associated diseases and abnormalities of fish and shellfish: a review. - Fish. Bull., U.S. 76, 717-749.

Wise, J. P. (Ed.), 1974. The United States marine fishery resource. Contr. NOAA-NMFS MARMAP 1, 1-379. 